\title{
Epidemiology of Pervasive Developmental Disorders
}

\author{
ERIC FOMBONNE \\ Department of Psychiatry, Montreal Children's Hospital of the McGill University Health Centre, Montreal, Quebec, Canada H3Z 1P2
}

\begin{abstract}
This article reviews the results of 43 studies published since 1966 that provided estimates for the prevalence of pervasive developmental disorders (PDDs), including autistic disorder, Asperger disorder, PDD not otherwise specified, and childhood disintegrative disorder. The prevalence of autistic disorder has increased in recent surveys and current estimates of prevalence are around 20/10,000, whereas the prevalence for PDD not otherwise specified is around 30/10,000 in recent surveys. Prevalence of Asperger disorder is much lower than that for autistic disorder and childhood disintegrative disorder is a very rare disorder with a prevalence of about 2/100,000. Combined all together, recent studies that have examined the whole spectrum of PDDs have consistently provided estimates in the 60-70/10,000 range, making PDD one of the most frequent childhood neurodevelopmental disorders. The meaning of the increase in prevalence in recent decades is reviewed. There is evidence that the broadening of the concept, the expansion of diagnostic criteria, the development of services, and improved awareness of the condition have played a major role in explaining this increase, although it cannot be ruled out that other factors might have also contributed to that trend. (Pediatr Res 65: 591-598, 2009)
\end{abstract}

$\mathrm{T}$ his article provides an up-to-date review of methodological features and substantive results of published epidemiologic surveys of pervasive developmental disorders (PDD). PDDs are also sometimes referred to as autism spectrum disorders, and represent a class of disorders sharing similar features and including distinct diagnoses: autistic disorder, Asperger syndrome (AS), PDD not otherwise specified (PDDNOS), and childhood disintegrative disorder (CDD). Throughout, the term PDD refers to the broad class of disorders comprising all three specific diagnoses. This review updates previous reviews $(1,2)$ with the inclusion of newly published surveys in the last 3 years. The specific questions addressed in this review are a) what is the range of prevalence estimates for autism and related PDDs? and; b) is the incidence of PDD increasing?

\section{Selection of Studies}

The studies were identified through systematic searches from the major scientific literature databases (MEDLINE, PSYCINFO) using search words "autism," "PDD," "epidemiology," "prevalence," and from prior reviews $(1,2)$. Only

Received July 22, 2008; accepted December 13, 2008.

Correspondence: Eric Fombonne, M.D., McGill University, Department of Psychiatry, The Montreal Children's Hospital, 4018 St. Catherine St. W., Montreal, Quebec H3Z 1P2, Canada; e-mail: eric.fombonne@mcgill.ca studies published in the English language were included. Overall, 53 studies published between 1966 and 2008 were selected, which surveyed PDDs in clearly demarcated, nonoverlapping samples. Of these, 43 studies provided information on the prevalence of autistic disorder and 19 studies provided estimates on the prevalence of all PDDs combined.

\section{Survey Descriptions}

Surveys were conducted in 17 countries and over half of the results have been published since 2000. Details on the precise sociodemographic composition and economical activities of the area surveyed in each study were not always available; most studies were, however, conducted in predominantly urban areas. The age range of the population included in the surveys is spread from birth to early adult life but most surveys have included school-age samples with an overall median age of 8.0. There was a huge variation in the size of the population surveyed. Studies with small sample sizes tended to yield higher prevalence than studies with larger sample sizes (2).

\section{Study Designs}

Some studies have relied on existing administrative databases (3-5) or on national registers (6) for case identification. Most investigations have relied on a two-stage or multistage approach to identify cases in underlying populations. The first screening stage of these studies often consisted of sending letters or brief screening scales requesting school and health professionals to identify possible cases of autism. Each investigation varied in several key aspects of this screening stage. First, the coverage of the population varied enormously from one study to another. In addition, the surveyed areas varied in terms of service development as a function of the specific

Abbreviations: ADI-R, Autism Diagnostic Interview-Revised; AS, Asperger Syndrome; CARS, Childhood Autism Rating Scale; CDD, childhood disintegrative disorder; CDER, Client Development and Evaluation Report; DSM-IV, Diagnostic and Statistical Manual, 4th Edition; DSM-III, Diagnostic and Statistical Manual, 3rd Edition; DSM-III-R, Diagnostic and Statistical Manual, 3rd Edition-Revised; ICD-10, International Classification of Diseases, 10th Edition; PDD, pervasive developmental disorder; PDDNOS, pervasive developmental disorder not otherwise specified; RDC, Research Diagnostic Criteria 
educational or health care systems of each country and of the year of investigation. Second, the type of information sent out to professionals invited to identify children varied from simple letters including a few clinical descriptors of autism-related symptoms or diagnostic checklists rephrased in nontechnical terms, to more systematic screening based on questionnaires or rating scales of known reliability and validity. Third, participation rates in the first screening stages were variable although refusal rates tended to be very low.

Few studies provided an estimate of the reliability of the screening procedure. The sensitivity of the screening methodology is also difficult to gauge in autism surveys, as the proportion of false negatives was usually not estimated. Prevalence estimates must, therefore, be seen as underestimates of "true" prevalence proportions.

Participation rates in second stage assessments were also generally high. The source of information used to determine caseness usually involved a combination of informants and data sources, with a direct assessment of the person with autism in about half of the studies. However, surveys of large populations $(7,8)$ did not include a direct diagnostic assessment of subjects. Nevertheless, the methods developed by the Centers for Disease Controls for recent large surveys have been described in detail and rely on a multisource multiinformant screening of the population, abstraction of key developmental data, and review by panels of expert clinicians who apply best-estimate procedures of known reliability and validity $(7,8)$.

The assessments were conducted with various diagnostic instruments, ranging from a classical clinical examination to the use of batteries of standardized measures that included, in the most recent studies, gold standard diagnostic tools such as the Autism Diagnostic Interview-Revised (ADI-R) or the Autism Diagnostic Observational Schedule (ADOS). The precise diagnostic criteria retained to define caseness varied according to the study and, to a large extent, reflected historical changes in classification systems. Thus, Kanner's criteria, Lotter's, and Rutter's definitions were used in surveys conducted before 1980, whereas DSM-based definitions took over thereafter as well as ICD-10 since 1990. Kielinen et al. (9) have shown that a 2- to 3-fold variation in prevalence of autism can result from applying different diagnostic criteria to the same survey data.

\section{Prevalence Estimations}

Autistic disorder. Data on children with autistic disorder were available in 43 surveys (Table 1). The mean male:female ratio was 4.2:1. Prevalence estimates ranged from 0.7/10,000 to $72.6 / 10,000$ (Table 1; 3,5,6,9,10-48). Prevalence was negatively correlated with sample size, and small-scale studies tended to report higher prevalence proportions. The correlation between prevalence and year of publication was statistically significant and studies with prevalence more than 7/10,000 were all published since 1987 . These findings point toward an increase in prevalence estimates in the last 15-20 years. The interpretation of this trend is discussed below. In 18 studies published since 2000, the prevalence proportion ranged from 7.2 to $40.5 / 10,000$. The average prevalence was $20.6 / 10,000$, a value that can be used as the best current estimate for the prevalence of autistic disorder.

Unspecified PDDs-PDDNOS. Several studies have provided useful information on rates of syndromes similar to autism but falling short of strict diagnostic criteria for autistic disorder $(1,2)$. Different labels have been used to characterize them such as "autistic-like" disorders or the triad of impairments involving impairments in reciprocal social interaction, communication, and imagination (49) that would correspond to current diagnostic labels such as atypical autism and PDDNOS. Seventeen of the 43 surveys yielded separate estimates of the prevalence of these atypical autistic syndromes, with 14 studies showing higher prevalence for the nonautism disorders than that for autism. The ratio of the prevalence of nonautistic PDD to the prevalence of autism had a mean value of 1.8 , which, assuming a 20.6/10,000 prevalence for autistic disorder, translates into an average prevalence estimate of 37.1/ 10,000 for PDDNOS. This group has been much less studied in previous epidemiologic studies but progressive recognition of its importance and relevance to autism has led to changes in the design of more recent epidemiologic surveys (see below) that are now designed to include these less typical forms in their case definition. It should be clear from these figures that they represent a very substantial group of children whose treatment needs are likely to be as important as those of children with autism.

$A S$ and childhood disintegrative disorder. Epidemiologic studies of AS are sparse, probably due to the fact that it was acknowledged as a separate diagnostic category only recently in both ICD-10 and DSM-IV. Only two epidemiologic surveys have been conducted, which specifically investigated its prevalence $(34,50)$. However, only a handful $(n<5)$ of cases were identified in these surveys, with the resulting estimates being extremely imprecise. By contrast, other recent autism surveys have consistently identified smaller numbers of children with AS than those with autism within the same survey. In nine of 10 such surveys, the ratio of autism to AS prevalence in each survey was above unity, suggesting that the prevalence of AS was consistently lower than that for autism (Table 2; 5,32$36,40,42,45,48)$. How much lower is difficult to establish from existing data, but a ratio of 3 or 4 to 1 would appear an acceptable, albeit conservative, conclusion based on this limited available evidence. This translates into a prevalence proportion for AS, which would be $1 / 3$ to $1 / 4$ that of autism. We, therefore, used for subsequent calculations an estimate of $6 / 10,000$ for AS, recognizing the strong limitations of available data on AS.

Eight surveys provided data on CDD (51). Prevalence estimates ranged from 0 to $9.2 / 100,000$. The pooled estimate based on eight identified cases and a total surveyed population of 406,660 children, was 2.0/100,000. The upper-bound limit of the associated confidence interval $(4.0 / 100,000)$ indicates that CDD is a very rare condition, with about one case to occur for every 103 cases of autistic disorder.

Prevalence for combined PDDs. Taking the aforementioned estimates, the prevalence for all PDDs is estimated to be $63.7 /$ 
10,000 (i.e., the sum of estimates for autism (20.6/10,000), PDDNOS (37.1/10,000), and AS (6/10,000)). These calculations are, however, approximations and provide only an estimated value for the prevalence estimates. Recent epidemiologic surveys that have focused on PDD as the case definition, yielded similar results with even higher values in several studies (Table 3; $4-8,35,37,40,42,45,46,48,52-58)$. The median prevalence of 19 studies in Table 3 is 63.5/10,000. The more recent CDC surveys $(7,8)$ have confirmed slightly higher prevalence for the United States. In these studies, the case definition chosen was that of a PDD as opposed to the narrower approach focusing on autistic disorder that was typical of previous surveys. Investigators were concerned with any combination of severe developmental abnormalities occurring in one or more of the three symptomatic domains defining PDD and autism. Case finding techniques were proactive, relying on multiple and repeated screening phases, involving both different informants at each phase and surveying the same cohorts at different ages, which certainly maximized the sensitivity of case identification. In several studies, assessments were performed with standardized diagnostic measures (i.e., ADI-R and ADOS), which match well the more dimensional approach retained for case definition. Conducted in different regions and countries by different teams, the convergence of estimates around 60 to 70 per 10,000 for all PDD combined is striking especially when coming from studies with improved methodology, and it represents the best estimate for the prevalence of PDDs currently available. This prevalence roughly translates into one child of 150 suffering from a PDD. However, some studies have reported prevalence proportions that are two to three times higher $(46,58)$.

\section{Is There An Autism Epidemic?}

To examine the hypothesis of a secular increase in the prevalence of autism, it is crucial to differentiate prevalence (the proportion of individuals in a population who suffer from a defined disorder) from incidence (the number of new cases occurring in a population over a period of time). Both prevalence and incidence estimates will be inflated when case definition is broadened and case ascertainment is improved. Time trends in prevalence or incidence can, therefore, only be gauged in investigations that hold these parameters under strict control over time. These methodological requirements must be borne in mind while reviewing the evidence for a secular increase in the prevalence of PDDs.

Five approaches to assess this question have been used in the literature.

Referral statistics. Increasing numbers of children referred to specialist services or known to special education registers have been taken as evidence for an increased incidence of autismspectrum disorders. However, trends over time in referred samples are confounded by many factors such as referral patterns, availability of services, heightened public awareness, decreasing age at diagnosis, and changes over time in diagnostic concepts and practices, to name only a few. Failure to control for these confounding factors was obvious in some recent reports such as the widely quoted reports from California educational services.
(http://www.dds.ca.gov/Autism/docs/AutismReport2003.pdf, http://www.dds.ca.gov/Autism/docs/autism_report_1999.pdf).

Strong evidence of "diagnostic switching" was produced in California (59) and in all US states (60), indicating that a relatively high proportion of children previously diagnosed as having mental retardation were now identified as having a PDD diagnosis. Decreased age at diagnosis has also been shown to contribute to the rising numbers of children diagnosed with PDD (61). In the United Kingdom, Jick et al. (62) have shown that the incidence of specific developmental disorders (including language disorders) decreased by about the same amount that the incidence of diagnoses of autism increased in boys born from 1990 to 1997. A more recent UK study (63) has shown that up to $66 \%$ of adults previously diagnosed with developmental language disorders would meet diagnostic criteria for a broad definition of PDD. Overall, evidence from these referral statistics is very weak and proper epidemiologic studies are needed to assess secular changes in the incidence of a disorder.

Comparison of cross-sectional epidemiologic surveys. As shown earlier, epidemiologic surveys of autism each possess unique design features which could account almost entirely for between-studies variations in prevalence proportions, and time trends in the prevalence of autism are, therefore, difficult to gauge from published prevalence estimates. The significant correlation previously mentioned between prevalence and year of publication could merely reflect increased efficiency over time in case identification methods used in surveys as well as changes in diagnostic concepts and practices $(9,30,39,60,63)$. In studies using capture-recapture methods, it is apparent that up to one third of prevalent cases may be missed by an ascertainment source, even in recently conducted studies (57). The most convincing evidence that method factors could account for most of the variability in published prevalence estimates comes from a direct comparison of eight recent surveys conducted in the United Kingdom and the United States (2). In each country, four surveys were conducted around the same year and with similar age groups. As there is no reason to expect huge between-area differences in prevalence, prevalence estimates should, therefore, be comparable within each country. However, there was a 6-fold variation in prevalence for UK surveys and a 14-fold variation in US figures. In each set of studies, high estimates derived from surveys where intensive population-based screening techniques were used, whereas lower prevalence proportions were obtained from studies relying on passive administrative methods for case finding. Because no passage of time was involved, the magnitude of these gradients in prevalence can only be attributed to differences in case identification methods across surveys. Even more convincing evidence comes from the large survey by the CDC on 408,000 US children aged 8 and born in 1994 (8) where an average prevalence of $66 / 10,000$ was reported for 14 US states. However, there was more than a 3 -fold variation in state-specific prevalence proportions that ranged from a low 33/10,000 for Alabama to a high of $106 / 10,000$ in New Jersey. These substantial differences reflected ascertainment variability across sites in a study that was otherwise performed with 


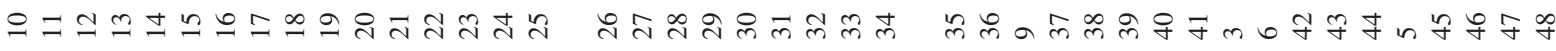

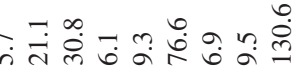

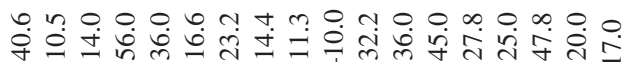

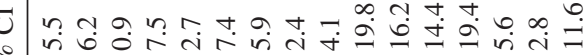

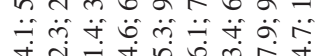

ö के й

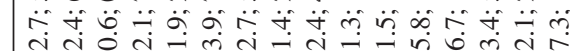

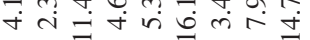

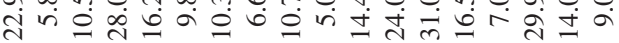

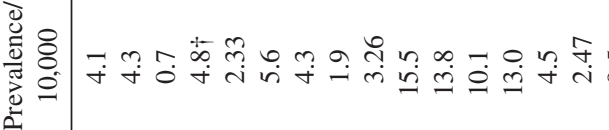

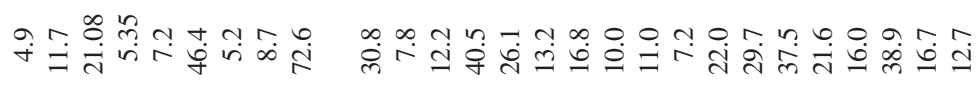

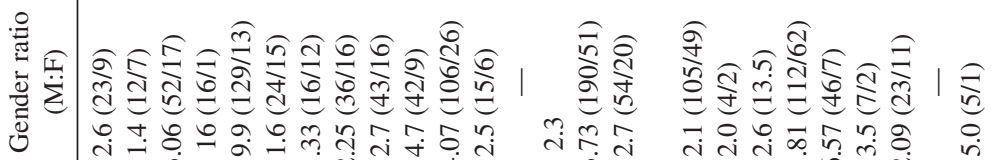

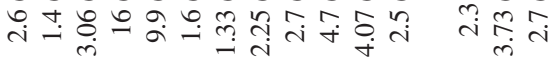

i

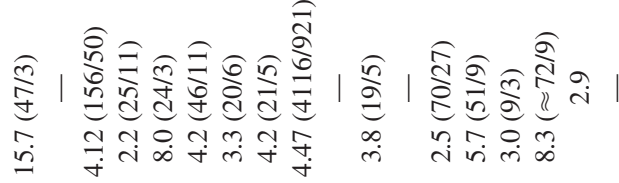

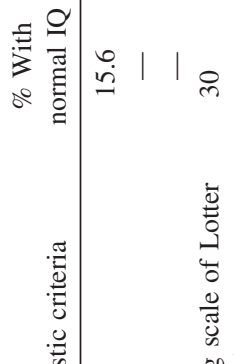

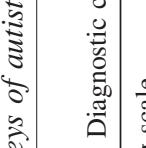

.

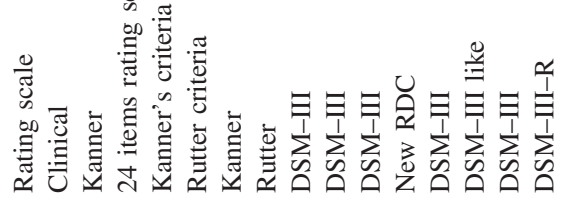

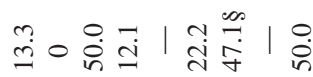

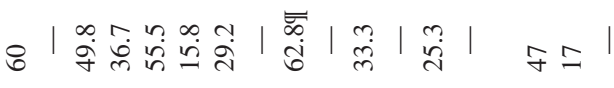

(-)

$\frac{n}{0 .}$

焉

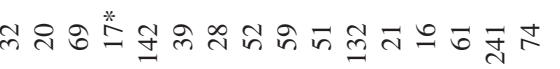

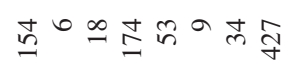

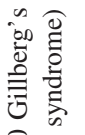

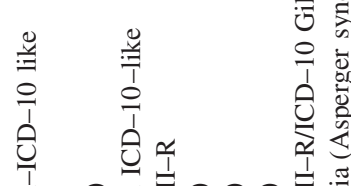

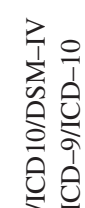

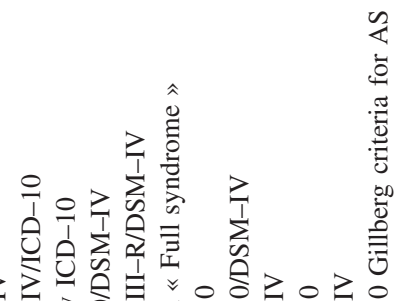

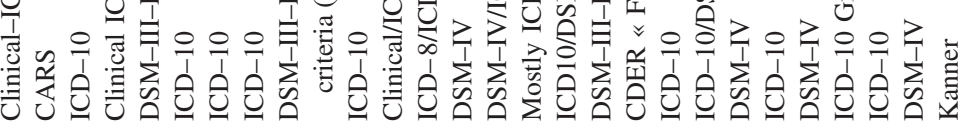

×

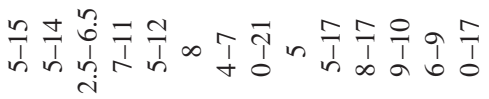

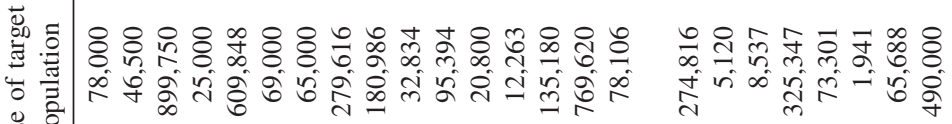

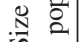

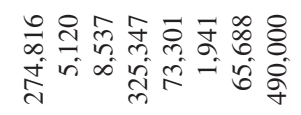

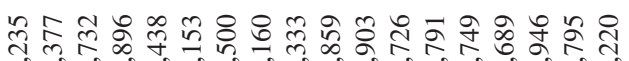

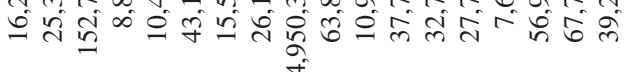

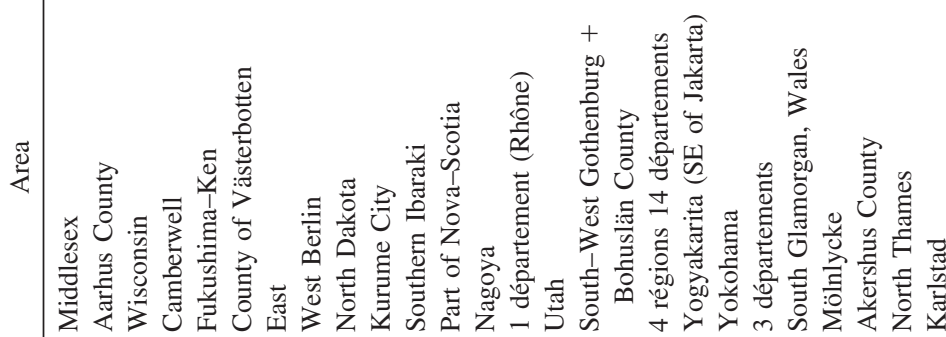

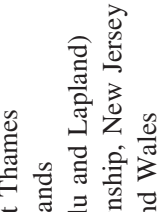

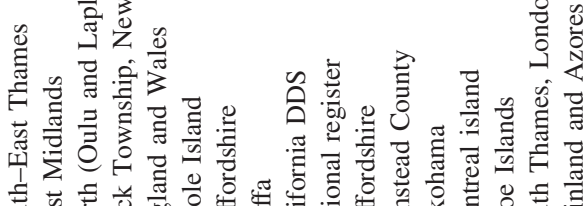

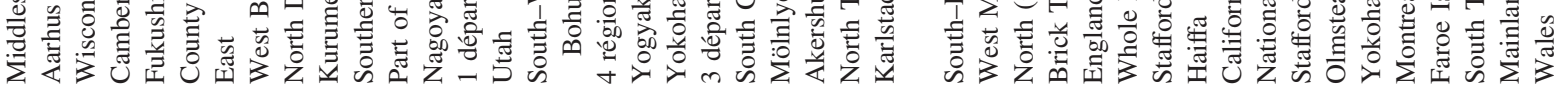

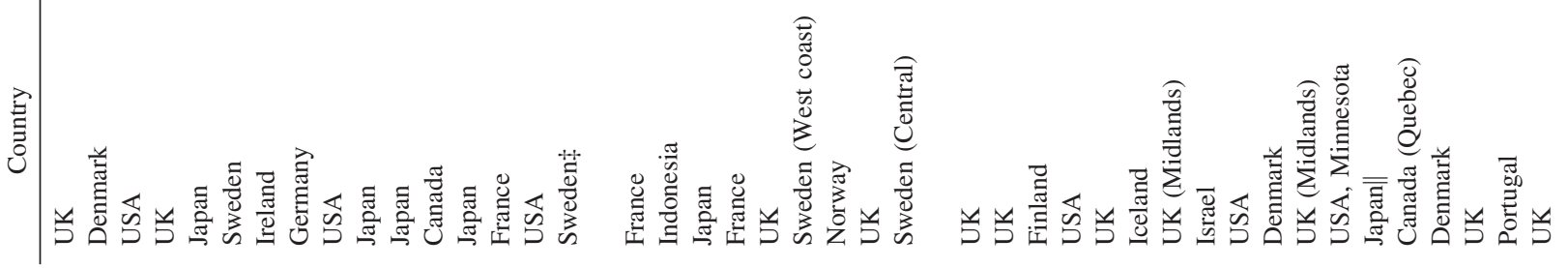


Table 1. (Continued)

\footnotetext{
* This number corresponds to the sample described in Wing and Gould (1979).

$\dagger$ This prevalence corresponds to the first published paper on this survey and is based on 12 subjects amongst children aged 5 to 14 years.

\$ For the Goteborg surveys by Gillberg et al. (Gillberg, 1984; Steffenburg and Gillberg, 1986; Gillberg et al., 1991) a detailed examination showed that there was overlap between the samples included in the 3 surveys; consequently only the last survey has been included in this table.

$\S$ In this study, mild mental retardation was combined with normal IQ, whereas moderate and severe mental retardation were grouped together.

II This proportion is likely to be overestimated and to reflect an underreporting of mental retardation in the CDER evaluations.

$\|$ This figure was calculated by the author and refers to prevalence data (not cumulative incidence) presented in the paper (the $\mathrm{M} / \mathrm{F}$ ratio is based on a subsample).
}

the same methods and at the same time, and in children born in the same year. Thus, no inference on trends in the incidence of PDDs can be derived from a simple comparison of prevalence estimates over time, since studies conducted at different periods are likely to differ even more with respect to their methodology.

Repeat surveys in defined geographical areas. Repeated surveys, using the same methodology and conducted in the same geographical area at different points in time, can poten- tially yield useful information on time trends provided that methods are kept relatively constant. The Göteborg studies $(25,64)$ provided three prevalence estimates, which increased over a short period of time. However, different age groups were included in each survey. Other factors such as improved detection among the mentally retarded, cases born to immigrant parents, change in local services, and a progressive broadening of the definition of autism over time were hypothesized by the authors to account for the trend (64). Similarly, studies conducted in Japan at different points in time in Toyota (58) and Yokohama $(28,44)$ showed rises in prevalence that their authors interpreted as reflecting the effect of both improved population screening of preschoolers and of a broadening of diagnostic concepts and criteria.

Two separate surveys of children born 1992-1995 and 1996-1998 in Staffordshire in the United Kingdom (40) were performed with rigorously identical methods for case definition and case identification. The prevalence for combined PDDs was comparable and not statistically different in the two surveys (42), suggesting no upward trend in overall prevalence of PDDs during the studies time interval. In the two recent CDC surveys $(7,8)$, the prevalence at six sites included in the 2000 and 2002 surveys remained constant at

Table 2. Asperger syndrome $(A S)$ in recent autism surveys

\begin{tabular}{|c|c|c|c|c|c|c|c|c|c|c|}
\hline \multicolumn{5}{|c|}{ Assessment } & \multicolumn{2}{|c|}{ Autism } & \multicolumn{4}{|c|}{ Asperger syndrome } \\
\hline $\begin{array}{c}\text { Size of } \\
\text { population }\end{array}$ & $\begin{array}{l}\text { Age } \\
\text { group }\end{array}$ & Informants & Instruments & Diagnostic criteria & $\mathrm{N}$ & $\begin{array}{c}\text { Prevalence/ } \\
10,000\end{array}$ & $\mathrm{~N}$ & $\begin{array}{c}\text { Prevalence/ } \\
10,000\end{array}$ & $\begin{array}{l}\text { Autism/AS } \\
\text { ratio }\end{array}$ & References \\
\hline 65,688 & $3-14$ & Parent Child & $\begin{array}{l}\text { Parental Interview }+ \\
\text { direct observation, } \\
\text { CARS, ABC }\end{array}$ & ICD-10 & 32 & 4.9 & 2 & 0.3 & 16.0 & 32 \\
\hline 490,000 & $0-16$ & Record & $\begin{array}{l}\text { Rating of all data } \\
\text { available in child } \\
\text { record }\end{array}$ & ICD-10 & 427 & 8.7 & 71 & 1.4 & 6.0 & 33 \\
\hline 826 & $6.7-7.7$ & $\begin{array}{l}\text { Child Parent } \\
\text { Professional }\end{array}$ & $\begin{array}{l}\text { ADI-R, Griffiths } \\
\text { Scale or WISC, } \\
\text { Asperger } \\
\text { Syndrome } \\
\text { Screening } \\
\text { Questionnaire }\end{array}$ & $\begin{array}{l}\text { DSM-III-R/ICD- } \\
10 \text { Gillberg's } \\
\text { criteria } \\
\text { (Asperger } \\
\text { syndrome) }\end{array}$ & 6 & 72.6 & 4 & 48.4 & 1.5 & 34 \\
\hline 25,377 & $1-4.9$ & Records & $\begin{array}{l}\text { ADI-R Available } \\
\text { data }\end{array}$ & $\begin{array}{c}\text { DSM-III-R } \\
\text { DSM-IV } \\
\text { ICD-10 }\end{array}$ & 54 & - & 16 & - & 3.4 & 36 \\
\hline 16,235 & 7 & $\begin{array}{l}\text { Parents Child } \\
\text { Other data }\end{array}$ & ADI-R Psychometry & ICD-10 DSM-IV & 45 & 27.7 & 5 & 3.1 & 9.0 & 35 \\
\hline 15,500 & $2.5-6.5$ & $\begin{array}{l}\text { Child Parent } \\
\text { Professional }\end{array}$ & $\begin{array}{l}\text { ADI-R, } 2 \text { wk } \\
\text { multidisciplinary } \\
\text { assessment, } \\
\text { Merrill-Palmer, } \\
\text { WPPSI }\end{array}$ & ICD-10 DSM-IV & 26 & 16.8 & 13 & 8.4 & 2.0 & 40 \\
\hline 10,903 & $2.5-6.5$ & $\begin{array}{l}\text { Child Parent } \\
\text { Professional }\end{array}$ & $\begin{array}{l}\text { ADI-R, } 2 \text { wk } \\
\text { multidisciplinary } \\
\text { assessment, } \\
\text { Merrill-Palmer, } \\
\text { WPPSI }\end{array}$ & ICD-10 DSM-IV & 24 & 22.0 & 12 & 11.0 & 2.0 & 42 \\
\hline 7,689 & $8-17$ & $\begin{array}{l}\text { Parent Child } \\
\text { Professional }\end{array}$ & $\begin{array}{l}\text { DISCO, WISC-R, } \\
\text { ASSQ }\end{array}$ & $\begin{array}{l}\text { ICD-10 Gillberg } \\
\text { AS criteria }\end{array}$ & 21 & 28.0 & 20 & 26.0 & 1.1 & 45 \\
\hline 27,749 & $5-17$ & $\begin{array}{l}\text { School } \\
\text { registry }\end{array}$ & Clinical & DSM-IV & 60 & 21.6 & 28 & 10.1 & 2.1 & 5 \\
\hline 39,220 & $0-17$ & $?$ & Clinical & $\begin{array}{l}\text { Kanner, Gillberg } \\
\text { AS criteria }\end{array}$ & 50 & 12.7 & 139 & 35.4 & 0.36 & 48 \\
\hline
\end{tabular}


FOMBONNE

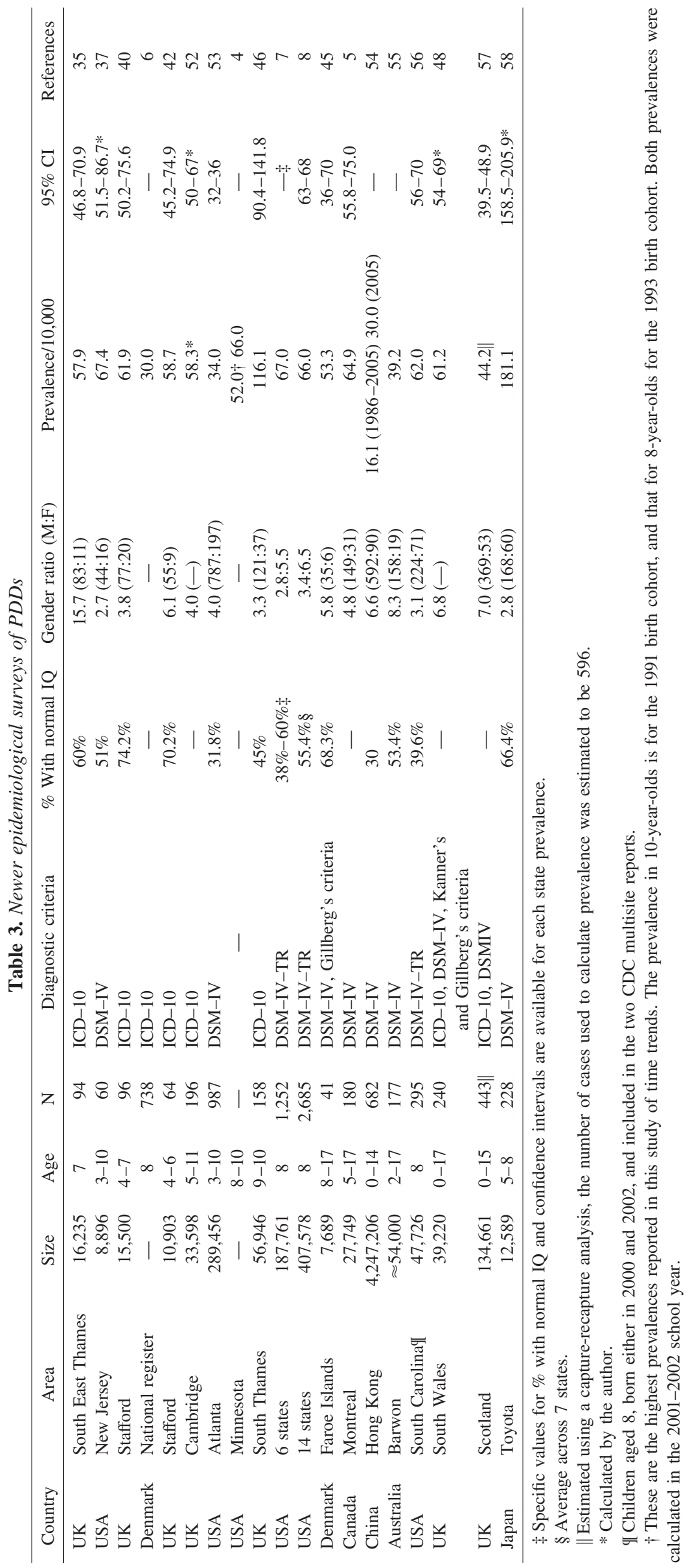


four sites, and increased in two states (Georgia and West Virginia) most likely due to improved quality of survey methods at these sites.

Successive birth cohorts. In large surveys encompassing a wide age range, increasing prevalence among most recent birth cohorts could be interpreted as indicating a secular increase in the incidence of the disorder, provided that alternative explanations can confidently be ruled out. This analysis was used in two large French surveys $(26,29)$. The surveys included birth cohorts from 1972 to 1985 (735,000 children, 389 of whom had autism), and, pooling the data of both surveys, age-specific prevalence showed no upward trend (29).

Several analyses of special educational disability in the United States $(4,60)$ showed increased numbers of PDD children in schools, but the increase was not specific to autism. These analyses also showed a marked period effect that identified the early 1990 s as the period where the prevalence estimates started to go up in all ages and birth cohorts, coinciding closely with the inclusion of PDDs in the federal Individual with Disabilities Educational Act (IDEA) funding and reporting mechanism in the United States.

Incidence studies. The few incidence studies showed an upward trend in incidence over short periods of time. In one of the largest study of 1410 subjects, there was a 10-fold increase in the rate of first recorded diagnoses of PDDs in United Kingdom general practice medical records from 1988-1992 to 2000-2001 (65). The increase was more marked for PDDs other than autism but the increase in autism was also obvious. However, none of these studies investigations could determine the impact of changes over time in diagnostic criteria, improved awareness and service availability on the upward trend. The same conclusions apply to other incidence studies $(36,43,44,54)$.

As it stands now, the recent upward trend in estimates of prevalence cannot be directly attributed to an increase in the incidence of the disorder. There is good evidence that changes in diagnostic criteria, diagnostic substitution, changes in the policies for special education, and the increasing availability of services are responsible for the higher prevalence figures. Most of the existing epidemiologic data are inadequate to properly test hypotheses on changes in the incidence of autism in human populations. Accordingly, the possibility that a true increase in the incidence of PDDs has also contributed to the upward trend in prevalence estimates cannot and should not be ruled out based on available data.

\section{CONCLUSION}

Epidemiologic surveys of autism and PDDs have now been carried out in several countries. Methodological differences in case definition and case finding procedures make between survey comparisons difficult to perform. However, from recent studies, a best estimate of 60 to 70/10,000 (equivalences $=6$ to $7 / 1,000$; or 0.6 to $0.7 \%$; or one child in about 150 children) can be confidently derived for the prevalence of autism spectrum disorders. The results of this review, that incorporates findings from very large scale studies such as those conducted by the Center for Disease Control, provide robust evidence that PDDs are much more common than previously thought. In addition, as illustrated in the CDC surveys that used the same methods in 16 US states in a defined birth cohort of American children, there are states where the prevalence was underestimated due to lower service development and lower sensitivity. Thus, the current estimates are only average figures and it may be expected that future prevalence proportions will be higher in future surveys. In some countries, and in some US states, recent prevalence estimates are above the $1 \%$ mark. Current evidence does not strongly support the hypothesis of a secular increase in the incidence of autism but power to detect time trends is seriously limited in existing datasets. Although it is clear that prevalence estimates have gone up over time, this increase most likely represents changes in the concepts, definitions, service availability, and awareness of autistic-spectrum disorders in both the lay and professional public. To assess whether the incidence has increased, method factors that account for an important proportion of the variability in prevalence must be tightly controlled. The possibility that a true change in the underlying incidence has contributed to higher prevalence figures remains, however, to be adequately tested.

Taking 60 and 70/10,000 as two working prevalence figures for the combination of all PDDs, and using population estimates for the United States of July 1, 2002, it can be estimated that between 486,000 and 567,000 subjects younger than 20 years suffer from a PDD in the United States. These figures carry straightforward implications for current and future needs in services and early educational intervention programs.

\section{REFERENCES}

1. Fombonne E 2003 Epidemiological surveys of autism and other pervasive developmental disorders: an update. J Autism Dev Disord 33:365-382

2. Fombonne E 2005 Epidemiology of autistic disorder and other pervasive developmental disorders. J Clin Psychiatry 66:3-8

3. Croen LA, Grether JK, Hoogstrate J, Selvin S 2002 The changing prevalence of autism in California. J Autism Dev Disord 32:207-215

4. Gurney JG, Fritz MS, Ness KK, Sievers P, Newschaffer CJ, Shapiro EG 2003 Analysis of prevalence trends of autism spectrum disorder in Minnesota [comment]. Arch Pediatr Adolesc Med 157:622-627

5. Fombonne E, Zakarian R, Bennett A, Meng L, McLean-Heywood D 2006 Pervasive developmental disorders in Montreal, Quebec, Canada: prevalence and links with immunizations. Pediatrics 118:e139-e150

6. Madsen KM, Hviid A, Vestergaard M, Schendel D, Wohlfahrt J, Thorsen P, Olsen J, Melbye M 2002 A population-based study of measles, mumps, and rubella vaccination and autism. N Engl J Med 347:1477-1482

7. Autism and Developmental Disabilities Monitoring Network Surveillance Year 2000 Principal Investigators; Center for Disease Control and Prevention 2007 Prevalence of autism spectrum disorders-autism and developmental disabilities monitoring network, six sites, United States, 2000. MMWR Surveill Summ 56:1-11

8. Autism and Developmental Disabilities Monitoring Network Surveillance Year 2002 Principal Investigators; Center for Disease Control and Prevention 2007 Prevalence of autism spectrum disorders-autism and developmental disabilities monitoring network, 14 sites, United States, 2002. MMWR Surveill Summ 56:12-28

9. Kielinen M, Linna S-L, Moilanen I 2000 Autism in Northern Finland. Eur Child Adolesc Psychiatry 9:162-167

10. Lotter V 1966 Epidemiology of autistic conditions in young children: I. Prevalence. Soc Psychiatry 1:124-137

11. Brask B 1972 A prevalence investigation of childhood psychoses. In: Nordic Symposium on the Care of Psychotic Children. Barnepsychiatrist Forenin, Oslo

12. Treffert DA 1970 Epidemiology of infantile autism. Arch Gen Psychiatry 22:431438

13. Wing L, Yeates S, Brierly L, Gould J 1976 The prevalence of early childhood autism: comparison of administrative and epidemiological studies. Psychol Med 6:89-100 
14. Hoshino Y, Kumashiro H, Yashima Y, Tachibana R, Watanabe M 1982 The epidemiological study of autism in Fukushima-ken. Folia Psychiatr Neurol Jpn 36:115-124

15. Bohman M, Bohman I, Bjorck P, Sjoholm E 1983 Childhood psychosis in a northern Swedish county: some preliminary findings from an epidemiological survey. In: Schmidt M, Remschmidt H (eds) Epidemiological Approaches in Child Psychiatry. Georg Thieme Verlag, Stuttgart, Germany, pp 164-173

16. McCarthy P, Fitzgerald M, Smith M 1984 Prevalence of childhood autism in Ireland Ir Med J 77:129-130

17. Steinhausen H-C, Gobel D, Breinlinger M, Wohlloben B 1986 A community survey of infantile autism. J Am Acad Child Psychiatry 25:186-189

18. Burd L, Fisher W, Kerbeshan J 1987 A prevalence study of pervasive developmental disorders in North Dakota. J Am Acad Child Adolesc Psychiatry 26:700-703

19. Matsuishi T, Shiotsuki M, Yoshimura K, Shoji H, Imuta F, Yamashita F 1987 High prevalence of infantile autism in Kurume City, Japan. J Child Neurol 2:268-271

20. Tanoue Y, Oda S, Asano F, Kawashima K 1988 Epidemiology of infantile autism in Southern Ibaraki, Japan: differences in prevalence in birth cohorts. J Autism Dev Disord 18:155-166

21. Bryson SE, Clark BS, Smith IM 1988 First report of a Canadian epidemiological study of autistic syndromes. J Child Psychol Psychiatry 29:433-445

22. Sugiyama T, Abe T 1989 The prevalence of autism in Nagoya, Japan: a total population study. J Autism Dev Disord 19:87-96

23. Cialdella P, Mamelle N 1989 An epidemiological study of infantile autism in a French Department (Rhone): a research note. J Child Psychol Psychiatry 30:165-175

24. Ritvo ER, Freeman BJ, Pingree C, Mason-Brothers A, Jorde L, Jenson W, McMahon WM, Petersen PB, Mo A, Ritvo A 1989 The UCLA-University of Utah epidemiologic survey of autism: prevalence. Am J Psychiatry 146:194-199

25. Gillberg C 1984 Infantile autism and other childhood psychoses in a Swedish urban region. Epidemiological aspects. J Child Psychol Psychiatry 25:35-43

26. Fombonne E, du Mazaubrun C 1992 Prevalence of infantile autism in four French regions. Soc Psychiatry Psychiatr Epidemiol 27:203-210

27. Wignyosumarto S, Mukhlas M, Shirataki S 1992 Epidemiological and clinical study of autistic children in Yogyakarta, Indonesia. Kobe J Med Sci 38:1-19

28. Honda H, Shimizu Y, Misumi K, Niimi M, Ohashi Y 1996 Cumulative incidence and prevalence of childhood autism in children in Japan. Br J Psychiatry 169:228 235

29. Fombonne E, Du Mazaubrun C, Cans C, Grandjean H 1997 Autism and associated medical disorders in a French epidemiological survey. J Am Acad Child Adolesc Psychiatry 36:1561-1569

30. Webb EV, Lobo S, Hervas A, Scourfield J, Fraser WI 1997 The changing prevalence of autistic disorder in a Welsh health district. Dev Med Child Neurol 39:150-152

31. Arvidsson T, Danielsson B, Forsberg P, Gillberg C, Johansson M, Kjellgren G 1997 Autism in 3-6 year-old children in a suburb of Goteborg, Sweden. Autism 1:163173

32. Sponheim E, Skjeldal O 1998 Autism and related disorders: epidemiological findings in a Norwegian study using ICD-10 diagnostic criteria. J Autism Dev Disord 28:217-227

33. Taylor B, Miller E, Farrington C, Petropoulos M-C, Favot-Mayaud I, Li J, Waight P 1999 Autism and measles, mumps, and rubella vaccine: no epidemological evidence for a causal association. Lancet 353:2026-2029

34. Kadesjo B, Gillberg C, Hagberg B 1999 Brief report: autism and Asperger syndrome in seven-year-old children: a total population study. J Autism Dev Disord 29:327331

35. Baird G, Charman T, Baron-Cohen S, Cox A, Swettenham J, Wheelwright S, Drew A 2000 A screening instrument for autism at 18 months of age: a 6 year follow-up study. J Am Acad Child Adolesc Psychiatry 39:694-702

36. Powell JE, Edwards A, Edwards M, Pandit BS, Sungum-Paliwal SR, Whitehouse W 2000 Changes in the incidence of childhood autism and other autistic spectrum disorders in preschool children from two areas of the West Midlands, UK. Dev Med Child Neurol 42:624-628

37. Bertrand J, Mars A, Boyle C, Bove F, Yeargin-Allsopp M, Decoufle P 2001 Prevalence of autism in a United States population: the Brick Township, New Jersey, investigation. Pediatrics 108:1155-1161

38. Fombonne E, Simmons H, Ford T, Meltzer H, Goodman R 2001 Prevalence of pervasive developmental disorders in the British nationwide survey of child mental health. J Am Acad Child Adolesc Psychiatry 40:820-827

39. Magnusson P, Saemundsen E 2001 Prevalence of autism in Iceland. J Autism Dev Disord 31:153-163
40. Chakrabarti S, Fombonne E 2001 Pervasive developmental disorders in preschool children. JAMA 285:3093-3099

41. Davidovitch M, Holtzman G, Tirosh E 2001 Autism in the Haifa area-an epidemiological perspective. Isr Med Assoc J 3:188-189

42. Chakrabarti S, Fombonne E 2005 Pervasive developmental disorders in preschool children: confirmation of high prevalence. Am J Psychiatry 162:1133-1141

43. Barbaresi WJ, Katusic SK, Colligan RC, Weaver AL, Jacobsen SJ 2005 The incidence of autism in Olmsted County, Minnesota 1976-1997: results from a population-based study. Arch Pediatr Adolesc Med 159:37-44

44. Honda H, Shimizu Y, Rutter M 2005 No effect of MMR withdrawal on the incidence of autism: a total population study. J Child Psychol Psychiatry 46:572-579

45. Ellefsen A, Kampmann H, Billstedt E, Gillberg IC, Gillberg C 2007 Autism in the Faroe Islands: an epidemiological study. J Autism Dev Disord 37:437-444

46. Baird G, Simonoff E, Pickles A, Chandler S, Loucas T, Meldrum D, Charman T 2006 Prevalence of disorders of the autism spectrum in a population cohort of children in South Thames: the Special Needs and Autism Project (SNAP). Lancet $368: 210-215$

47. Oliveira G, Ataide A, Marques C, Miguel TS, Coutinho AM, Mota-Vieira L, Goncalves E, Lopes NM, Rodrigues V, Carmona da Mota H, Vicente AM 2007 Epidemiology of autism spectrum disorder in Portugal: prevalence, clinical characterization, and medical conditions. Dev Med Child Neurol 49:726-733

48. Latif AH, Williams WR 2007 Diagnostic trends in autistic spectrum disorders in the South Wales valleys. Autism 11:479-487

49. Wing L, Gould J 1979 Severe impairments of social interaction and associated abnormalities in children: Epidemiology and classification. J Autism Dev Disord 9:11-29

50. Ehlers S, Gillberg C 1993 The epidemiology of Asperger syndrome: A total population study. J Child Psychol Psychiatry 34:1327-1350

51. Fombonne E 2006 Past and future perspectives on autism epidemiology. In: Moldin S, Rubenstein J (eds) Understanding Autism: From Basic Neuroscience to Treatment. CRC Press, Boca Raton, Florida

52. Scott FJ, Baron-Cohen S, Bolton P, Brayne C 2002 Brief report: prevalence of autism spectrum conditions in children aged 5-11 years in Cambridgeshire, UK. Autism 6:231-237

53. Yeargin-Allsopp M, Rice C, Karapurkar T, Doernberg N, Boyle C, Murphy C 2003 Prevalence of autism in a US metropolitan area [comment]. JAMA 289:49-55

54. Wong VC, Hui SL 2008 Epidemiological study of autism spectrum disorder in China. J Child Neurol 23:67-72

55. Icasiano F, Hewson P, Machet P, Cooper C, Marshall A 2004 Childhood autism spectrum disorder in the Barwon region: a community based study. J Paediatr Child Health 40:696-701

56. Nicholas JS, Charles JM, Carpenter LA, King LB, Jenner W, Spratt EG 2008 Prevalence and characteristics of children with autism-spectrum disorders. Ann Epidemiol 18:130-136

57. Harrison MJ, O'Hare AE, Campbell H, Adamson A, McNeillage J 2006 Prevalence of autistic spectrum disorders in Lothian, Scotland: an estimate using the "capturerecapture" technique. Arch Dis Child 91:16-19

58. Kawamura Y, Takahashi O, Ishii T 2008 Reevaluating the incidence of pervasive developmental disorders: impact of elevated rates of detection through implementation of an integrated system of screening in Toyota, Japan. Psychiatry Clin Neurosci 62:152-159

59. Eagle RS 2004 Commentary: Further commentary on the debate regarding increase in autism in California. J Autism Dev Disord 34:87-88

60. Shattuck PT 2006 Diagnostic substitution and changing autism prevalence. Pediatrics 117:1438-1439

61. Wazana A, Bresnahan M, Kline J 2007 The autism epidemic: fact or artifact? J Am Acad Child Adolesc Psychiatry 46:721-730

62. Jick H, Kaye JA, Black C 2003 Epidemiology and possible causes of autism Changes in risk of autism in the U.K. for birth cohorts 1990-1998. Pharmacotherapy 23:1524-1530

63. Bishop DV, Whitehouse AJ, Watt HJ, Line EA 2008 Autism and diagnostic substitution: evidence from a study of adults with a history of developmental language disorder. Dev Med Child Neurol 50:341-345

64. Gillberg C, Steffenburg S, Schaumann H 1991 Is autism more common now than ten years ago? Br J Psychiatry 158:403-409

65. Smeeth L, Cook C, Fombonne E, Heavey L, Rodrigues LC, Smith PG, Hall AJ 2004 MMR vaccination and pervasive developmental disorders: a case-control study. Lancet 364:963-969 